\title{
Management of Soft Tissue Sarcomas in Extremities: Variation in Treatment Recommendations and Surveillance According to Specialty and Continent
}

\author{
Ibtissam Acem, BS ${ }^{1,2}$, Merel M. Smit, $\mathbf{B S}^{2}$, Cornelis Verhoef, MD, $\mathrm{PhD}^{\mathbf{1}}$, Winan J. van Houdt, MD, $\mathrm{PhD}^{\mathbf{3}}$, \\ Rick L. Haas, MD, PhD ${ }^{4,5}$, Jos A. van der Hage, MD, PhD ${ }^{6}$, Dirk J. Grünhagen, MD, PhD ${ }^{1}$, and \\ Michiel A. J. van de Sande, MD, $\mathrm{PhD}^{2}$ \\ ${ }^{1}$ Department of Surgical Oncology and Gastrointestinal Surgery, Erasmus MC Cancer Institute, Erasmus Medical Centre, \\ Rotterdam, The Netherlands; ${ }^{2}$ Department of Orthopedic Oncology, Leiden University Medical Centre, Leiden, The \\ Netherlands; ${ }^{3}$ Department of Surgical Oncology, The Netherlands Cancer Institute, Amsterdam, The Netherlands; \\ ${ }^{4}$ Department of Radiotherapy, The Netherlands Cancer Institute, Amsterdam, The Netherlands; ${ }^{5}$ Department of \\ Radiotherapy, Leiden University Medical Centre, Leiden, The Netherlands; ${ }^{6}$ Department of Surgical Oncology, Leiden \\ University Medical Centre, Leiden, The Netherlands
}

\begin{abstract}
Background. This study aimed to provide an insight into clinical decision-making and surveillance strategy of sarcoma specialists for patients with primary soft tissue sarcoma of the extremities (eSTS). The secondary aim was to quantify the role of patient- and tumor-specific factors in the perioperative management.

Methods. Members of sarcoma societies were sent a Webbased 21-item survey about eSTS management. The survey concerned only primary resectable high-grade eSTS in adults.

Results. The study enrolled 396 respondents. The majority of the surgical specialists thought the evidence for perioperative chemotherapy (CTX) for high-grade eSTS was insufficient. Radiotherapy (RTX) was less frequently offered in Asia than in North America and Europe. The specialties and continents also differed regarding the importance of patient and tumor characteristics influencing RTX and CTX recommendation. For surveillance after initial treatment outpatient visits, chest computed tomography (CT) scans, and magnetic resonance images of the extremity were the methods primarily used. The specialists
\end{abstract}

(C) The Author(s) 2021

First Received: 7 December 2020

Accepted: 17 March 2021;

Published Online: 10 May 2021

I. Acem, BS

e-mail: i.acem@erasmusmc.nl in North America preferred chest CT scan over chest x-ray, whereas those in Asia and Europe had no clear preference. Discussion. Specialty and continent are important factors contributing to the variation in clinical practice, treatment recommendations, and surveillance of patients with primary resectable high-grade eSTS.

Soft tissue sarcomas (STSs) are a heterogeneous group of tumors with a mesenchymal origin. This group of malignant tumors has more than 80 histologic subtypes and accounts for $1 \%$ of all adult malignancies. ${ }^{1}$ Soft tissue sarcomas are rare, with an estimated incidence of about 5 patients per 100,000 persons in Europe every year. ${ }^{2,3}$ All this together makes it challenging to generate high-level evidence for the management of primary STS.

The National Comprehensive Cancer Network guideline $(\mathrm{NCCN})^{4}$ and the European Society of Medical Oncology guideline $(\mathrm{ESMO})^{5}$ are two broadly used international clinical practice guidelines for the management and surveillance of STS. The two guidelines are similar and agree that surgery is the cornerstone for the treatment of soft tissue sarcoma of the extremities (eSTS). ${ }^{4,5}$ Perioperative radiotherapy (RTX) is recommended to improve local control in settings wherein adequate margins are not possible or for high-grade, deep-seated tumors, or tumors $5 \mathrm{~cm}$ in size or larger. ${ }^{4,5}$ Perioperative chemotherapy (CTX) is not standard practice, but it can be offered as an option to high-risk patients after shared decision-making., 
Although several studies have shown that adherence to guidelines results in better patient outcomes, 32-70\% of patients with STS are not consistently treated in accordance with the clinical guidelines. ${ }^{6-11}$ This study aimed to acquire insight into the variation of eSTS management by assessing the influence of clinical specialty and continent on clinical practice and surveillance. Additionally, this study investigated the extent to which selected patient and disease characteristics are used to distinguish between high- and low-risk patients and the extent to which these factors are used in clinical decision-making for perioperative treatment.

\section{METHODS}

\section{Survey Design}

The survey used for this study was developed by the authors after literature review and a small focus group discussion. Pilot testing of the survey was performed internally for content and face validity at the Leiden University Medical Center, The Netherlands Cancer Institute, and the Erasmus MC Cancer Institute in The Netherlands. Online survey software (Qualtrics; Provo, UT, USA) was used to administer the survey, which was open to respondents for a 4-month period from 2 March to 2 July 2020.

The study population received an invitation e-mail from the participating sarcoma societies describing the purpose of the survey and containing an electronic link to the online survey software. The study population received two new invitations within a time frame of 4 months as a reminder. An opt-out option was provided in the request e-mail.

The survey included questions pertaining to respondent characteristics, the current clinical practice, the importance of selected patient and disease characteristics in the recommendation of perioperative treatment, and follow-up evaluation. Most of the questions required scoring of characteristics on a 5-point Likert scale. The survey was designed with closed-ended questions to allow a completion time of only about $10 \mathrm{~min}$. The respondents were allowed to leave a question blank.

The 21-item survey is available in Appendix 1. The questions in the survey concerned only primary eSTS in adults (age $\geq 18$ years). Additional treatment with isolated limb perfusion, immunotherapy, and regional hyperthermia were not considered in this survey.

The survey responses were anonymously collected, and no information that could potentially identify a respondent was collected. This study was approved by the institutional Medical Ethical Committee Leiden-Den Haag-Delft (N20.016) and complied with the regulations governing
Good Clinical Research Practice and General Data Protection Regulation.

\section{Study Population}

The target group for the questionnaire comprised clinically active international members of the Connective Tissue Oncology Society (CTOS), the European MusculoSkeletal Oncology Society (EMSOS), and the Asia Pacific Musculoskeletal Tumor Society (APMSTS). Respondents who were not physicians or did not have a self-declared interest in STS were excluded from the study.

\section{Real-World Data}

Findings on perioperative treatment in eSTS were compared with the real-world data of 6265 patients who had surgically treated primary high-grade eSTS (age $\geq 18$ years) from 21 sarcoma centers. Details on this retrospective cohort were reported by Acem et al. ${ }^{12}$

\section{Statistical Analysis}

All analyses were performed using the statistical program R (R Core Team, Vienna, Austria). ${ }^{13}$ Respondent characteristics and other categorical variables are described in absolute values and proportions. The 5-point Likert scale scores (5-pt LSS) were displayed in proportions and means (mean 5-point LSS) with standard deviations (SDs).

All the questions were stratified by specialty and continent. The respondents with a specialty in both medical and radiation oncology (clinical oncology) were classified as medical oncologists. The respondents from Africa, Central and South America, Australia, New Zealand, and Oceania were excluded from the analyses stratified by continent due to insufficiently large sample sizes.

Differences in outcomes on the 5-pt LSS were tested with the one-way analysis of variance (ANOVA) test. Differences in categorical outcomes were tested with the chi-square test or Fisher's exact test when the value of at least one cell in the contingency table was below 5. Bonferroni correction was used to account for multiple testing. Blank questions were considered missing and not imputed.

\section{RESULTS}

\section{Demographics}

The survey was received by 1386 potential respondents and completed by 428 respondents (response rate, 30.9\%), 396 of whom met the inclusion criteria. The study excluded 
respondents without a special interest in STS $(n=31)$ and respondents who were not physicians $(n=1)$. The last question of the survey was answered by 255 respondents $(64.4 \%)$. Appendix 2 presents a flowchart of the respondent inclusion.

The baseline characteristics of the respondents are depicted in Table 1. Most of the respondents were orthopedic oncologists $(43.2 \%, n=171)$ practiced in Europe $(44.9 \%, n=155)$ and had more than 15 years of experience after their fellowship $(36.9 \%, n=146)$.

\section{Distinction Between High- and Low-Risk Patients}

The characteristics primarily used to distinguish between high- and low-risk eSTS patients were grade (mean 5-pt LSS, 4.93), histologic subtype (mean 5-pt LSS, 4.65), and size (mean 5-pt LSS, 4.51) (Fig. 1). Gender (mean 5-pt LSS, 1.52) and age (mean 5-pt LSS, 2.66) were

TABLE 1 Baseline characteristics of the respondents

\begin{tabular}{ll}
\hline Characteristics & $\begin{array}{l}\text { Overall } \\
(n=396) \\
n(\%)\end{array}$ \\
\hline
\end{tabular}

\begin{tabular}{|c|c|}
\hline \multicolumn{2}{|l|}{ Specialty } \\
\hline Medical oncology & $89(22.5)$ \\
\hline Orthopedic oncology & $171(43.2)$ \\
\hline Radiation oncology & $28(7.1)$ \\
\hline Surgical oncology & $83(21.0)$ \\
\hline Other $^{\mathrm{a}}$ & $25(6.3)$ \\
\hline \multicolumn{2}{|c|}{ Years since completion of fellowship } \\
\hline I am a fellow in training & $15(3.8)$ \\
\hline$<5$ years & $73(18.5)$ \\
\hline $5-10$ years & $90(22.8)$ \\
\hline $11-15$ years & $65(16.5)$ \\
\hline$\geq 15$ years & $151(38.3)$ \\
\hline Missing & 2 \\
\hline \multicolumn{2}{|l|}{ Current practice location } \\
\hline Africa & $3(0.8)$ \\
\hline Asia & $83(21.0)$ \\
\hline Australia/New Zealand/Oceania & $16(4.0)$ \\
\hline Central/South America & $7(1.8)$ \\
\hline Europe & $155(39.1)$ \\
\hline North America & $132(33.3)$ \\
\hline \multicolumn{2}{|l|}{ Number of new cases annually } \\
\hline$<5$ & $28(7.1)$ \\
\hline $5-25$ & $95(24.0)$ \\
\hline $25-50$ & $92(23.2)$ \\
\hline$\geq 50$ & $181(45.7)$ \\
\hline
\end{tabular}

${ }^{a}$ Including pediatric and adolescent oncology and pathology the least important factors used to distinguish between high- and low-risk eSTS patients.

For surgical specialties, extent of tumor necrosis on MRI (mean 5-pt LSS, 3.51) and infiltrative growth pattern (mean 5-pt LSS, 4.12) were more important for distinguishing between high- and low-risk patients than nonsurgical specialties (mean 5-pt LSS, 3.51 vs $2.84[p<$ $0.001]$ and 4.12 vs 3.56 [ $p<0.001]$, respectively). For nonsurgical specialties, size (mean 5-pt LSS, 4.75) was more important for distinguishing between high- and low-risk patients than surgical specialties (mean 5-pt LSS, 4.40; $p<$ $0.001)$. The use of patient and disease characteristics stratified by specialty are depicted in Appendix 3.

To distinguish between high- and low-risk patients, the specialists in Asia and Europe gave a higher rating of importance than the specialists in North America for extent of tumor necrosis on MRI (mean 5-pt LSS, 3.75 vs 2.80 [ $p<0.001]$ and 3.43 vs $2.80[p<0.001]$, respectively) and infiltrative growth pattern (mean 5-pt LSS, 4.21 vs 3.71 [ $p<0.001]$ and 4.11 vs 3.71 [ $p=0.004]$, respectively).

\section{Current Practice of RTX in the Management of High- Grade eSTS}

Of the 301 respondents, $142(47.2 \%)$ treated their highrisk eSTS patients frequently $(\geq 75 \%)$ with perioperative RTX. In Asia, RTX was offered less often (17.5\%) than in Europe $(52.1 \% ; p<0.001)$ or North America $(62.4 \% ; p<$ 0.001) (Fig. 2a). This was in accordance with the realworld data showing that $19.6 \%$ of the patients received RTX in Asia compared with $62.2 \%$ in Europe $(p<0.001)$ and $74.3 \%$ in Europe and North America $(p<0.001)$ (Appendix 4).

\section{Factors Influencing RTX Recommendation}

The factors most likely to influence perioperative RTX recommendation were the margins achieved (mean 5-pt LSS, 4.58), the anticipated margins (mean 5-pt LSS, 4.63), and grade (mean 5-pt LSS, 4.59) (Fig. 3). The least important factors influencing RTX recommendation were gender (mean 5-pt LSS, 1.38) and presence of a genetic prognostic markers (mean 5-pt LSS, 2.44).

For surgical specialties, infiltrative growth pattern was a more important factor influencing RTX recommendation (mean 5-pt LSS, 4.13) than nonsurgical specialties (mean 5-pt LSS, 3.51; $p<0.001)$. For nonsurgical specialties, grade (mean 5-pt LSS, 4.74), performance score (mean 5-pt LSS, 3.33), and oncologic history (mean 5-pt LSS, 2.82) were more important factors influencing RTX recommendation than surgical specialties (mean 5-pt LSS: $4.52[p=0.025], 2.87[p=0.005]$, and $2.35[p=0.004]$, respectively). The use of patient and disease characteristics 
Mean 5-pt LSS (SD)
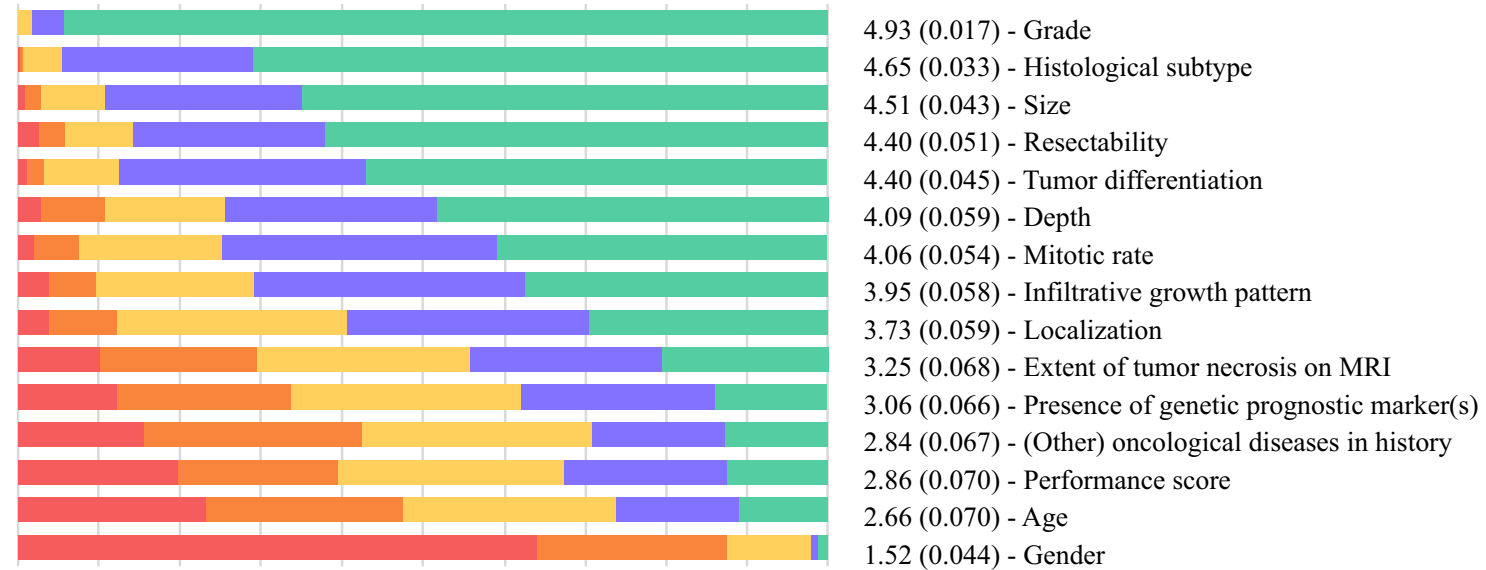

1: Never $\square$ 2: Seldom $\square$ : Sometimes $\quad$ 4: Frequently $\square$ : Always

FIG. 1 Use of patient and disease characteristics to distinguish between high- and low-risk patients with soft tissue sarcoma of the extremity (eSTS) $(n=348)$. 5-pt LSS 5-point Likert scale score, SD standard deviation

FIG. 2 What percentage of your patients with high-grade soft tissue sarcoma of the extremity (eSTS) receive perioperative treatment? a Radiotherapy.

b Chemotherapy.

FIG. 3 Factors influencing radiotherapy (RTX) recommendation $(n=291) .5$-pt LSS, 5-point Likert scale score. $\mathrm{SD}$, standard deviation.
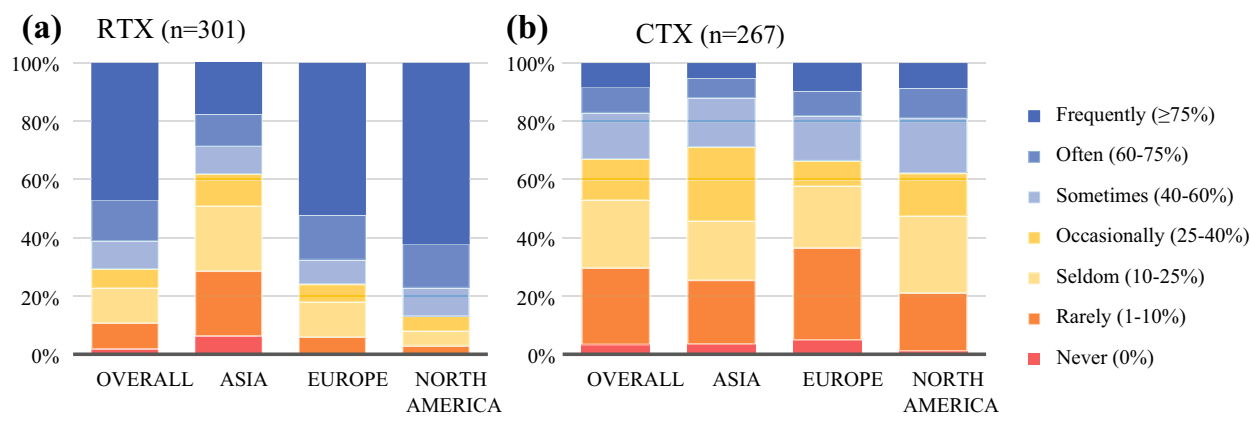

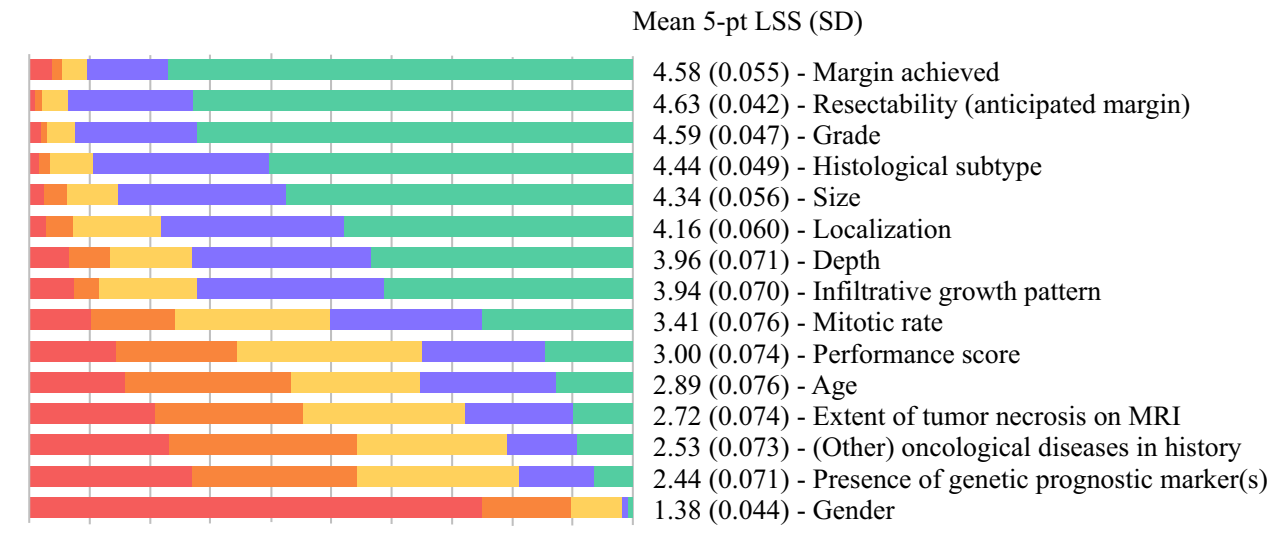

$\begin{array}{lllllllllll}0 \% & 10 \% & 20 \% & 30 \% & 40 \% & 50 \% & 60 \% & 70 \% & 80 \% & 90 \% & 100 \%\end{array}$

$\square 1:$ Never $₫ 2$ : Seldom $₫ 3$ : Sometimes $₫ 4$ : Frequently $\square 5$ : Always for RTX recommendation stratified by specialty are depicted in Appendix 5.

The specialists in Europe and North America rated grade for recommendation of perioperative RTX as more important than did the specialists in Asia (mean 5-pt LSS, 4.69 vs $4.22[p=0.003]$ and 4.83 vs $4.22[p<0.001]$, respectively). The specialists in North America rated size for the recommendation of perioperative RTX as more important than did the specialists in Asia and Europe (mean 5-pt LSS, 4.59 vs. $4.12[p=0.001]$ and 4.59 vs 4.29 [ $p=0.020]$, respectively). 


\section{Use of a Prediction Tool for RTX Recommendation}

Of the 296 respondents 219 (74\%) would consider using a prediction tool to indicate perioperative RTX for eSTS patients. Surgical oncologists $(92.2 \%)$ would consider using a prediction tool more often than orthopedic oncologists $(65.7 \% ; p<0.001)$. Specialists in Asia were less likely to consider using a prediction tool $(50 \%)$ than specialists in Europe $(76.1 \% ; p<0.001)$ or North America $(84.2 \% ; p<0.001)$.

\section{Current Practice of CTX in the Management of High- Grade eSTS}

Of the 276 respondents, 194 (70.3\%) treated more than $10 \%$ of their high-risk eSTS patients with perioperative CTX (Fig. 2b). No significant differences were found among continents in the use of CTX for high-grade eSTS. However, the real-world data showed a significant difference in the use of CTX among continents. In Asia, CTX was administered to $30.6 \%$ of the patients, whereas perioperative CTX was administered to $12.6 \%$ of the patients in Europe $(p<0.001)$ and to $3.3 \%$ of the patients North America $(p<0.001)$ (Appendix 4).

Of the 276 respondents, $173(62.7 \%)$ did not think the evidence was sufficient to use of perioperative CTX for patients with primary high-grade eSTS. The majority of the orthopedic $(74 \%)$ and surgical $(73.3 \%)$ oncologists $(p<$ 0.001 ) considered the current level of evidence for the role of CTX in high-grade eSTS to be insufficient, compared with $35.7 \%$ of the medical oncologists $(p<0.001)$. The attitude toward the role of perioperative CTX in primary high-grade eSTS did not differ across continents $(p=$ $0.137)$.

Older age ( $\geq 70$ years) was thought by $120(43 \%)$ of the 278 respondents to be an absolute contraindication for perioperative CTX.

\section{Factors Influencing CTX Recommendation}

The factors most likely to influence perioperative CTX recommendation were histologic subtype (mean 5-pt LSS, 4.73), grade (mean 5-pt LSS, 4.55), and size (mean 5-pt LSS, 4.20). The least important factors influencing CTX recommendation were gender (mean 5-pt LSS, 1.40) and extent of tumor necrosis on MRI (mean 5-pt LSS, 2.81) (Fig. 4a).

For the nonsurgical specialties, depth (mean 5-pt LSS, 3.92), location (mean 5-pt LSS, 3.62), performance score (mean 5-pt LSS, 4.36), and size (mean 5-pt LSS, 4.57) were more important factors influencing CTX recommendation than for the surgical specialties (mean 5-pt LSS, $3.41[p=0.004], 3.20[p=0.020], 3.64[p<0.001], 3.98$
[ $p<0.001]$, respectively). The use of patient and disease characteristics for CTX recommendation stratified by specialty are depicted in Appendix 6.

The specialists in Asia and Europe compared with the specialists in North America gave a higher rate of importance to extent of tumor necrosis on MRI (mean 5-pt LSS, 3.13 vs $2.30[p<0.001]$ and 3.08 vs $2.30[p<0.001]$, respectively) and infiltrative growth pattern (mean 5-pt LSS, 3.36 vs 2.76 [ $p=0.005]$ and 3.30 vs. 2.76 [ $p=$ 0.003], respectively) for a perioperative CTX recommendation.

The respondents would consider perioperative CTX primarily for synovial sarcoma (mean 5-pt LSS, 4.13), rhabdomyosarcoma (mean 5-pt LSS, 4.05), and myxoid liposarcoma with a round cell component (mean 5-pt LSS, 3.52). Perioperative CTX would be considered the least for fibrosarcoma (mean 5-pt LSS, 2.55) and myxofibrosarcoma (mean 5-pt LSS, 2.61) (Fig. 4b).

\section{Use of a Prediction Tool for CTX Recommendation}

Of the 277 respondents, 224 (80.9\%) would consider using a prediction tool to indicate perioperative CTX for eSTS patients. The specialists did not differ significantly in their attitude toward using a prediction tool for CTXs. The surgical oncologists (92.2\%) would consider using a prediction tool more often than the orthopedic oncologists $(65.7 \% ; p<0.001)$. The specialists in Asia were less likely to consider using a prediction tool $(62.7 \%)$ than the specialists in Europe $(82.9 \% ; p=0.007)$ or North America $(88.4 \% ; p<0.001)$.

\section{Follow-up Evaluation}

Outpatient visits, chest CT scan, and MRI of the extremity were the most common methods for follow-up evaluation. The frequency of each method declined with time (Table 2). The specialists in North America preferred chest CT scan over chest x-ray, with a median of four chest CT scans (mean, 3.33) in the first year compared with no chest $\mathrm{x}$-rays (mean, 0.860) $(p<0.001)$. After the first year, chest CT scan remained the preferred method in North America. Neither of the two methods were clearly preferred by specialists in Asia (median for CT vs. X-ray in the first year, 2 vs. $3 ; p=0.276$ ) or Europe (median for CT vs. $\mathrm{x}$-ray in the first year, 2 vs. $2 ; p=0.520$ ). In the first 5 years of surveillance, $29 \%$ of the respondents never used chest $\mathrm{x}$-ray, and $12 \%$ of the respondents never used chest CT scan. The outpatient clinic visit sequence used primarily in the first 5 years was 4-4-2-2-2 (16.9\%; 42 of 248).

Most of the respondents (56.9\%) felt comfortable to end the surveillance in patients with primary high-grade eSTS after 9 to 10 years of follow-up evaluation. Whereas $8.6 \%$ 


\section{(a) $(\mathrm{n}=268)$}

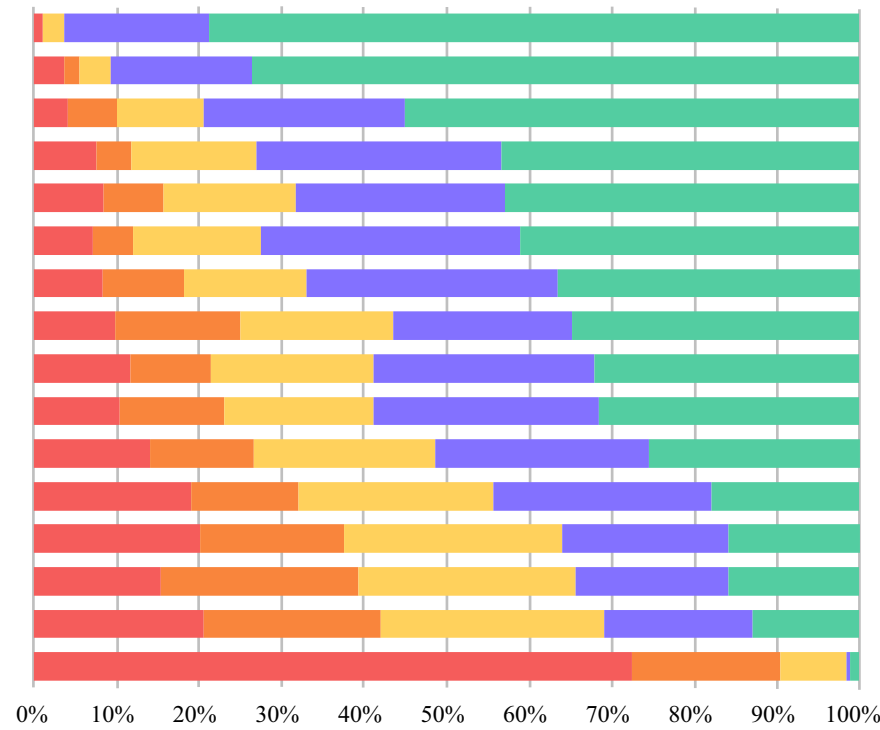

Mean 5-pt LSS (SD)

4.73 (0.038) - Histological subtype

4.55 (0.057) - Grade

$4.20(0.068)$ - Size

3.97 (0.074) - Tumor differentiation

3.87 (0.079) - Performance score

3.94 (0.073) - Age

3.77 (0.078) - Resectability (anticipated margin)

3.56 (0.084) - Margin achieved

3.58 (0.082) - Depth

3.57 (0.082) - Mitotic rate

$3.36(0.084)$ - Localization

3.11 (0.084) - Infiltrative growth pattern

2.94 (0.084) - Presence of genetic prognostic marker(s)

2.95 (0.081) - (Other) oncological diseases in history

2.81 (0.081) - Extent of tumor necrosis on MRI

$1.40(0.046)$ - Gender

Mean 5-pt LSS (SD)

4.13 (0.055) - Synovial sarcoma

4.05 (0.061) - Rhabdomyosarcoma

3.52 (0.079) - Myxoid round cell liposarcoma

3.49 (0.078) - Angiosarcoma

3.33 (0.079) - Undifferentiated pleomorphic sarcoma

3.18 (0.079) - Pleomorphic liposarcoma

2.93 (0.084) - Myxoid liposarcoma

3.05 (0.080) - Dedifferentiated liposarcoma

3.14 (0.074) - Leiomyosarcoma

2.90 (0.076) - Spindle cell sarcoma

$2.83(0.076)$ - MPNST

2.65 (0.083) - Alveolar soft part sarcoma

2.65 (0.078) - Epithelioid sarcoma

2.55 (0.072) - Fibrosarcoma

2.61 (0.073) - Myxofibrosarcoma

$0 \%$

$20 \%$

$$
40 \%
$$$$
60 \%
$$

$80 \% \quad 100 \%$

1: Never

2: Seldom

3: Sometimes
4: Frequently

5: Always
FIG. 4 a Factors influencing chemotherapy (CTX) recommendation. b For which histologic subtypes would you generally consider perioperative chemotherapy (CTX)? 5-pt LSS, 5-point Likert scale

would follow their patients for more than 16 years or for their whole lifetime, $26 \%$ of the respondents ended the surveillance after 5 to 6 years (Fig. 5)

\section{Discussion}

This study aimed to provide an insight into variation in the clinical decision-making processes between specialties and continents for the treatment of resectable high-grade eSTS. In addition, it aimed to analyze the relative role of specific tumor and patient factors in the clinical decision- score; SD, standard deviation; MPNST, malignant peripheral nerve sheath tumor

making with regard to the perioperative treatment of these patients. This study illustrates a wide variation among specialties and continents regarding the management and surveillance of patients with eSTS. Also, the results indicate a variation in risk factors considered to be indications for perioperative treatment. However, consensus exists regarding the risk factors frequently leading to recommendation for RTX (margins, grade, histologic subtype, size) and CTX (size, histologic subtype, grade).

This study demonstrated a notable difference in RTX practice among continents, in accordance with the included 
TABLE 2 Follow-up schedule per year after initial treatment for high-grade soft tissue sarcoma of the extremity (eSTS) $(n=252)$

\begin{tabular}{llllll}
\hline Method & \multicolumn{5}{l}{ Mean no. per year (median) } \\
\cline { 2 - 6 } & Year 1 & Year 2 & Year 3 & Year 4 & Year 5 \\
\hline Outpatient visit & $3.94(4)$ & $3.47(4)$ & $2.66(2)$ & $2.43(2)$ & $2.29(2)$ \\
Chest X-ray & $1.89(2)$ & $1.82(2)$ & $1.49(1)$ & $1.39(1)$ & $1.27(1)$ \\
Chest CT & $2.65(3)$ & $2.48(3)$ & $1.95(2)$ & $1.70(1)$ & $1.48(1)$ \\
Extremity x-ray & $1.17(0)$ & $0.968(0)$ & $0.807(0)$ & $0.892(0)$ & $0.743(0)$ \\
Extremity CT & $0.565(0)$ & $0.591(0)$ & $0.489(0)$ & $0.525(0)$ & $0.397(0)$ \\
Extremity MRI & $2.55(3)$ & $2.43(2)$ & $1.94(2)$ & $1.86(1)$ & $1.65(1)$ \\
PET-CT scan & $0.667(0)$ & $0.510(0)$ & $0.384(0)$ & $0.358(0)$ & $0.476(0)$ \\
\hline
\end{tabular}

$C T$ computed tomography, $M R I$ magnetic resonance imaging, $P E T$ positron emission tomography

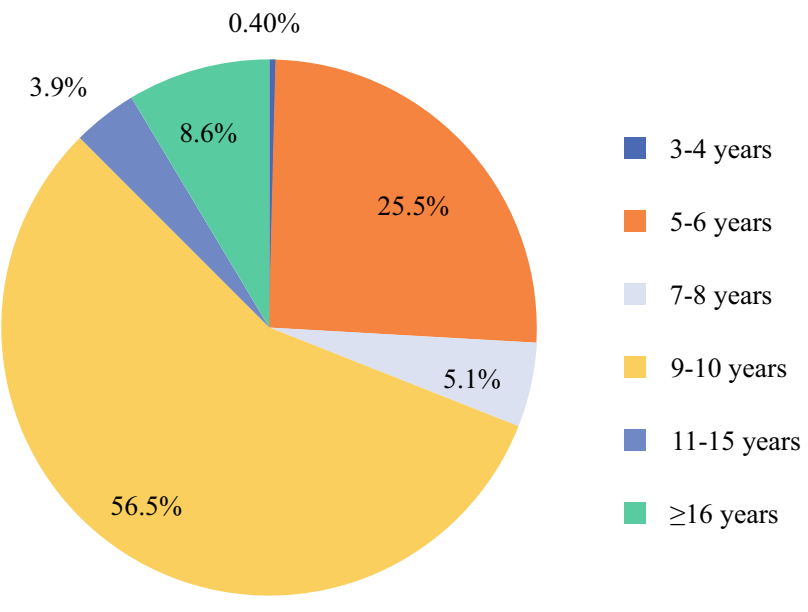

FIG. 5 Duration of follow-up period after primary treatment $(n=$ 255)

real-world data. ${ }^{12}$ In Europe and North America, most of the respondents treat $75 \%$ or more of their patients with high-grade resectable eSTS using perioperative RTX, compared with only $17.5 \%$ of the respondents in Asia. Also, we observed a greater variation of RTX use in Asia than in Europe and North America. These results are supported by a systematic review including 24 studies of the Asia-Pacific region in which the use of RTX ranged from 1 to $100 \%$ preoperatively and from 6 to $88 \%$ postoperatively. ${ }^{14}$ The on-average lower rates of RTX use and greater variation of RTX use in Asia might be explained by a generally lower accessibility to radiotherapy in certain Asia-Pacific regions. ${ }^{15}$

The survey did not demonstrate a difference in CTX practice among continents. However, a notable difference in CTX use among the continents was observed in the realworld data, with CTX administration more prevalent in Asia than in Europe or North America. ${ }^{12}$ However, the real-world data included only one high-volume center from North America and only Japanese centers from Asia. ${ }^{12}$

The attitude toward the role of CTX in the management of eSTS varies widely. More than $70 \%$ of the orthopedic and surgical oncologists did not think the evidence is sufficient for CTX in primary high-grade resectable eSTS, compared with $35 \%$ of the medical oncologists. Substantial variation also exists in the current practice of perioperative chemotherapy, with $30 \%$ of the respondents never or rarely using CTX, but with almost half of the respondents (47\%) using perioperative CTX for more than $25 \%$ of their patients with primary high-grade eSTS. The variation in CTX practice might reflect a difference in interpretation of the available evidence on the role of perioperative CTX in primary eSTS. Other factors that might explain the variation are the availability of perioperative treatment and the variety of compensation and health care systems.

Several studies have suggested that a selected group of high-risk patients might benefit from perioperative CTX. ${ }^{16,17}$ However, the identification of these high-risk patients remains challenging. Our study demonstrated that the most important factors physicians use to identify highrisk patients are grade, histologic subtype, and size. These factors also are included in prediction tools such as the Sarculator (Callegaro et al., Milan, Italy) and PERSARC (Van Praag et al., Leiden, The Netherlands). ${ }^{18,19}$ The respondents of this study were predominantly positive about using such prediction tools to select patients for perioperative treatment. Interestingly, genetic prognostic markers are less widely used in the identification of highrisk patients, whereas genetic prognostic markers seem promising for the identification of high-risk patients. Chibon et al. ${ }^{20}$ showed that the gene expression profile, CINSARC, was a strong independent predictor for progressive disease and might identify high-risk patients that could benefit from CTX. ${ }^{21,22}$

Physicians seem to use different factors as indicators for RTX compared with CTX, which makes sense considering that RTX aims to improve local control, whereas CTX aims to prevent distant disease. Surgical margins play an important role in the indication for RTX, as shown by Wasif et al. ${ }^{23}$ In contrast, the most important factor in the indication for CTX is histologic subtype. Physicians would 
consider perioperative CTX the most frequently for synovial sarcoma and rhabdomyosarcoma. The importance of using these factors in the indication for RTX and CTX provides an interesting insight into the clinical decisionmaking process of physicians. This could be helpful for future studies because it quantifies the importance of adjusting for these factors in any observational study analyzing the role of perioperative treatment.

The variation in administration of perioperative treatment among specialties and continents might arise from the lack of available evidence on eSTS management that may be sufficient to standardize clinical decision-making. The rarity of eSTS makes it challenging to conduct well-powered trials of perioperative treatment. Also, the multiple biologic subtypes, anatomic variability, and limited understanding of tumor biology and the tumor immune microenvironment of multiple subtypes impose difficulties on clinical trial design compared with clinical trials of perioperative treatment for other more prevalent cancers with more homogeneous populations. However, the variation in perioperative treatment also might arise from less knowledge of the literature outside a practitioner's clinical domain. ${ }^{23,24}$ In addition, the clinical guidelines leave room for interpretation and variation. ${ }^{4,5}$ These factors reflect the importance of a multidisciplinary expert board reaching consensus decisions and facilitating personalized sarcoma care.

Only a few studies have investigated the optimal routine follow-up policy for patients with localized high-grade eSTS. ${ }^{25,26}$ Therefore, the optimal frequency and intensity of the routine follow-up policy remains unclear. The current clinical guidelines recommend follow-up evaluation every 3 to 4 months in the first 2 to 3 years, then twice a year up to the fifth year and once a year thereafter. ${ }^{4,5}$ The guidelines do not specify whether chest CT scan or chest X-ray should be used in the follow-up evaluation. This study showed that physicians in North America have a clear preference for chest CT scan over chest x-ray, whereas in Asia and Europe, no preference between these methods was found. The variability of follow-up strategies found in this study and other studies demonstrates the urgent need for well-designed prospective studies on follow-up evaluation. ${ }^{27-30}$

This study had some limitations. Only closed-ended questions were used to minimize the completion time and to maximize the completion rate. This resulted in a simplification of the responses. To prevent a lack of depth in the questionnaire and to prevent question order bias, a broad range of answers were included and arranged alphabetically. We recognize that other variables not captured in the questionnaire may also influence the choice for perioperative treatment.

Additionally, the use of a survey had the inherent limitation of selection bias because only physicians inclined to respond took time to do so. Also, the survey was sent only to active members of selected sarcoma societies, with some continents and specialties underrepresented in this study, which might affect the generalizability of our results.

Although electronic dissemination of the survey enabled easy delivery and reply, many e-mail addresses were invalid, and many e-mails were bounced back from e-mail filters. This might partially explain our moderate response rate of $31 \%$. The high response rate $(79 \%)$ of those who did open the e-mail shows that once the e-mail was received by the respondents, most of them went on complete the survey.

In conclusion, although several studies have shown that adherence to clinical guidelines results in better patient outcomes, this study showed remarkable variation in the management of eSTS. Specialty and continent are important factors contributing to the variation in clinical practice, treatment recommendations, and surveillance of patients with primary resectable high-grade eSTS.

ACKNOWLEDGMENT This research did not receive any specific grant from funding agencies in the public, commercial, or not-forprofit sectors.

OPEN ACCESS This article is licensed under a Creative Commons Attribution 4.0 International License, which permits use, sharing, adaptation, distribution and reproduction in any medium or format, as long as you give appropriate credit to the original author(s) and the source, provide a link to the Creative Commons licence, and indicate if changes were made. The images or other third party material in this article are included in the article's Creative Commons licence, unless indicated otherwise in a credit line to the material. If material is not included in the article's Creative Commons licence and your intended use is not permitted by statutory regulation or exceeds the permitted use, you will need to obtain permission directly from the copyright holder. To view a copy of this licence, visit http://creativecommons. org/licenses/by/4.0/.

\section{APPENDIX 1: SURVEY}

\section{What is the Questionnaire About?}

To investigate the variation in treatment policies regarding localized high-grade (grade 2-3) soft tissue sarcomas of extremities (eSTS) and to get a better understanding of important patient and disease characteristics influencing disease management we would like to invite you to fill in this questionnaire.

The questionnaire consists of 20 questions. You can save the questionnaire at any time and complete it later. The questionnaire takes about 10 minutes to complete.

The questions in this questionnaire concern only primary (non-metastasized) high-grade soft tissue sarcomas of extremities in adults ( $\geq 18$ years). Additional treatment with isolated limb perfusion (ILP), immunotherapy and regional hyperthermia $(\mathrm{RH})$ are not considered in this questionnaire. 


\section{Respondent Characteristics}

1. Are you a physician with an interest in soft tissue sarcomas? Yes/no

2. What is your speciality?
a. Medical oncology
b. Orthopaedic oncology
c. Radiation oncology
d. Surgical oncology
e. Other

3. How many years have elapsed since completion of your fellowship?
a. I am a fellow in-training
b. $<5$ years
c. $5-10$ years
d. 11-15 years
e. $>15$ years
f. Other

4. Where do you practice?
a. Africa
b. Asia
c. Australia/New Zealand/Oceania
d. Central/South America
e. Europe
f. North America

5. How many new cases of extremity soft tissue sarcoma do you treat in your hospital annually? (Average experience over the last 5 years):
a. $<5$ per year
b. 5-25 per year
c. $25-50$ per year
d. $>50$ per year

\section{STS Management}

\section{General}

6. Which patient and/or disease characteristics do you use to distinguish between high-risk and low-risk STS patients on a scale of 1-5 (1: never, 5: always)?
a. Age
b. Depth
c. Extent of tumour necrosis on MRI
d. Gender
e. Grade
f. Histological subtype
g. Infiltrative growth pattern
h. Localization
i. Mitotic rate
j. Performance score (WHO/KPS)
$\mathrm{k}$. Presence of genetic prognostic marker(s)
1. Presence of (other) oncological diseases in history m. Resectability: anticipated margin R0-R1-R2
n. Size
o. Tumour differentiation

\section{Radiotherapy}

7. What percentage of your patients with high-grade (grade 2 or 3 ) primary eSTS receive (neo)adjuvant radiotherapy? (Scroll bar)

8. Which of the following patient and/or disease characteristics generally influence your choice for treatment with (neo)adjuvant radiotherapy on a scale of 1 (never) to 5 (always)?
a. Age
b. Depth
c. Extent of tumor necrosis on MRI
d. Gender
e. Grade
f. Histologic subtype
g. Infiltrative growth pattern
h. Localization
i. Margin achieved: R0-R1-R2
j. Mitotic rate
k. Performance score (WHO/KPS)
1. Presence of genetic prognostic marker(s)
$\mathrm{m}$. Presence of (other) oncologic diseases in history
n. Resectability: anticipated margin R0-R1-R2
o. Size
p. Tumor differentiation

9. When making decisions regarding radiotherapy in addition to surgery for patients with primary eSTS, at what cutoff value of the predicted 5-year local recurrence rate would you recommend (neo)adjuvant radiotherapy? (Scroll bar)*

10. When making decisions regarding radiotherapy in addition to surgery for patients with primary eSTS, at what cutoff value of the absolute 5-year local recurrence rate reduction (ARR) would you recommend (neo)adjuvant radiotherapy? (Scroll bar)*

11. Would you consider using a prediction tool for local recurrence, such as Sarculator or Persarc, to indicate (neo)adjuvant radiotherapy for eSTS patients? Yes/ no

\section{Chemotherapy}

12. What percentage of your patients with high-grade (grade 2 or 3 ) primary eSTS receive (neo)adjuvant chemotherapy? (Scroll bar)

13. Which of the following patient and/or disease characteristics generally influence your choice for treatment with (neo)adjuvant chemotherapy on a scale of 1 (never) to 5 (always)? 

a. Age
b. Depth
c. Extent of tumor necrosis on MRI
d. Gender
e. Grade
f. Histologic subtype
g. Infiltrative growth pattern
h. Localization
i. Margin achieved: R0-R1-R2
j. Mitotic rate
k. Performance score (WHO/KPS)
1. Presence of genetic prognostic marker(s)
$\mathrm{m}$. Presence of (other) oncologic diseases in history
n. Resectability: anticipated margin R0-R1-R2
o. Size
p. Tumor differentiation

14. For what predicted 5-year mortality risk do you consider (neo)adjuvant chemotherapy in addition to surgery for primary eSTS? (Scroll bar)*

15. For what absolute 5-year mortality risk reduction (ARR) do you consider chemotherapy in addition to surgery for primary eSTS? (Scroll bar)*

16. Do you think sufficient evidence exists for the use of (neo)adjuvant chemotherapy to treat primary highgrade (grade 2 or 3 ) resectable eSTS? Yes/no

17. Would you consider using a prediction tool for overall survival and/or distant metastasis risk, such as Sarculator or Persarc, to indicate (neo)adjuvant chemotherapy for eSTS patients? Yes/no

18. For which STS histologic subtypes (grade 2 or 3, deep-seated, $>5 \mathrm{~cm}$ ) would you generally consider (neo)adjuvant chemotherapy on a scale of 1 (never) to 5 (always)?

a. Alveolar soft part sarcoma

b. Angiosarcoma

c. Dedifferentiated liposarcoma

d. Epithelioid sarcoma

e. Fibrosarcoma

f. Leiomyosarcoma

g. Malignant peripheral nerve sheath tumor (MPNST)

h. Myxofibrosarcoma

i. Myxoid liposarcoma

j. Pleomorphic liposarcoma

k. Rhabdomyosarcoma

1. Round cell liposarcoma

m. Spindle cell sarcoma

n. Synovial sarcoma

o. Undifferentiated sarcoma

19. Would older age ( $>70$ years) be an absolute contraindication for (neo)adjuvant chemotherapy? Yes/ no
Follow-up Evaluation

20. What is your follow-up schedule after initial treatment (with surgery and [neo]adjuvant treatment if indicated) has been completed for primary highgrade eSTS? Please enter the number of times during each time interval.

\begin{tabular}{|c|c|c|c|c|c|}
\hline & $\begin{array}{l}1 \text { st } \\
\text { year }\end{array}$ & $\begin{array}{l}2 \text { nd } \\
\text { year }\end{array}$ & $\begin{array}{l}3 \text { rd } \\
\text { year }\end{array}$ & $\begin{array}{l}\text { 4th } \\
\text { year }\end{array}$ & $\begin{array}{l}5 \text { th } \\
\text { year }\end{array}$ \\
\hline \multicolumn{6}{|l|}{$\begin{array}{l}\text { Outpatient clinic } \\
\text { visit }\end{array}$} \\
\hline \multicolumn{6}{|l|}{ X-thorax } \\
\hline \multicolumn{6}{|l|}{ CT thorax } \\
\hline \multicolumn{6}{|l|}{ X-extremity } \\
\hline \multicolumn{6}{|l|}{ CT extremity } \\
\hline \multicolumn{6}{|l|}{ MRI extremity } \\
\hline PET-CT scan & & & & & \\
\hline
\end{tabular}

21. After how many years of disease-free survival would you feel comfortable to end the follow-up evaluation of your patient with primary high-grade eSTS?

*The results of questions $9,10,14,15$ have not been reported because these questions were interpreted in multiple ways. Therefore, the results were not reliable.

\section{APPENDIX 2: \\ FLOWCHART OF THE RESPONDENTS}

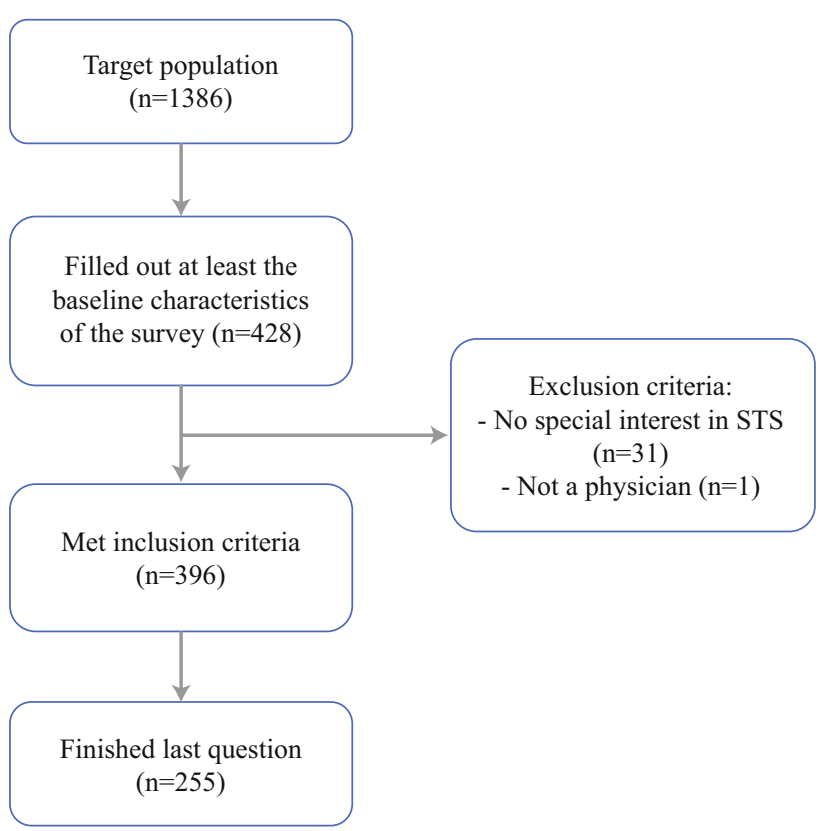




\section{APPENDIX 3: USE OF PATIENT AND DISEASE \\ CHARACTERISTICS TO DISTINGUISH BETWEEN \\ HIGH- AND LOW-RISK ESTS PATIENTS \\ STRATIFIED BY SPECIALTY}

\begin{tabular}{|c|c|c|c|c|c|c|}
\hline & \multicolumn{5}{|c|}{ Mean 5-point Likert scale score (standard error of the mean) } & \multirow[t]{2}{*}{$p$ Value* } \\
\hline & Overall & $\begin{array}{l}\text { Medical } \\
\text { oncology }\end{array}$ & $\begin{array}{l}\text { Orthopedic } \\
\text { oncology }\end{array}$ & $\begin{array}{l}\text { Radiation } \\
\text { oncology }\end{array}$ & $\begin{array}{l}\text { Surgical } \\
\text { oncology }\end{array}$ & \\
\hline Age & $2.66(0.070)$ & $2.61(0.147)$ & $2.69(0.098)$ & $2.08(0.223)$ & $2.83(0.168)$ & 0.090 \\
\hline Depth & $4.09(0.059)$ & $4.31(0.106)$ & $4.18(0.080)$ & $3.64(0.336)$ & $3.84(0.136)$ & 0.007 \\
\hline $\begin{array}{l}\text { Extent of tumor } \\
\text { necrosis on MRI }\end{array}$ & $3.25(0.068)$ & $2.88(0.143)$ & $3.53(0.096)$ & $2.71(0.244)$ & $3.45(0.147)$ & 0.000 \\
\hline Gender & $1.52(0.044)$ & $1.37(0.077)$ & $1.54(0.070)$ & $1.33(0.130)$ & $1.72(0.105)$ & 0.044 \\
\hline Grade & $4.93(0.017)$ & $4.93(0.036)$ & $4.91(0.029)$ & $5.00(0.000)$ & $4.92(0.035)$ & 0.602 \\
\hline Histologic subtype & $4.65(0.033)$ & $4.73(0.056)$ & $4.59(0.051)$ & $4.38(0.189)$ & $4.70(0.068)$ & 0.052 \\
\hline Infiltrative growth pattern & $3.95(0.058)$ & $3.50(0.117)$ & $4.15(0.079)$ & $3.79(0.225)$ & $4.07(0.136)$ & 0.000 \\
\hline Localization & $3.73(0.059)$ & $3.77(0.108)$ & $3.78(0.086)$ & $3.64(0.233)$ & $3.50(0.160)$ & 0.370 \\
\hline Mitotic rate & $4.06(0.054)$ & $4.11(0.103)$ & $4.07(0.079)$ & $3.54(0.233)$ & $4.20(0.121)$ & 0.046 \\
\hline Performance score & $2.86(0.070)$ & $3.00(0.157)$ & $2.84(0.098)$ & $2.83(0.274)$ & $2.88(0.162)$ & 0.833 \\
\hline $\begin{array}{l}\text { Presence of genetic } \\
\text { prognostic maker(s) }\end{array}$ & $3.06(0.066)$ & $3.02(0.148)$ & $3.13(0.094)$ & $2.75(0.250)$ & $2.95(0.151)$ & 0.478 \\
\hline $\begin{array}{l}\text { Presence of (other) oncologic } \\
\text { diseases in history }\end{array}$ & $2.84(0.067)$ & $2.65(0.142)$ & $2.97(0.095)$ & $2.79(0.282)$ & $2.67(0.153)$ & 0.184 \\
\hline Resectability & $4.40(0.051)$ & $4.43(0.101)$ & $4.45(0.074)$ & $4.46(0.217)$ & $4.20(0.123)$ & 0.337 \\
\hline Size & $4.51(0.043)$ & $4.81(0.059)$ & $4.52(0.056)$ & $4.56(0.164)$ & $4.10(0.132)$ & 0.000 \\
\hline Tumor differentiation & $4.40(0.045)$ & $4.20(0.118)$ & $4.46(0.059)$ & $4.40(0.173)$ & $4.51(0.076)$ & 0.088 \\
\hline
\end{tabular}

*Global $P$ value for difference in distribution among specialties. 
APPENDIX 4: PERIOPERATIVE THERAPY

IN A COHORT OF HIGH-GRADE ESTS PATIENTS

\begin{tabular}{lllll}
\hline & $\begin{array}{l}\text { Overall } \\
(n=6260) \\
n(\%)\end{array}$ & $\begin{array}{l}\text { Asia } \\
(n=1850) \\
n(\%)\end{array}$ & $\begin{array}{l}\text { Europe } \\
(n=3304) \\
n(\%)\end{array}$ & $\begin{array}{l}\text { North America }^{\mathrm{a}} \\
(n=1106) \\
n(\%)\end{array}$ \\
\hline $\begin{array}{l}\text { Surgical margin } \\
\text { R0 }\end{array}$ & $5338(85.3)$ & $1764(95.4)$ & $2630(79.6)$ & $944(85.4)$ \\
R1-R2 & $732(11.7)$ & $86(4.6)$ & $484(14.6)$ & $162(14.6)$ \\
Missing & $190(3.0)$ & $0(0)$ & $190(5.8)$ & $0(0)$ \\
Radiotherapy & $3016(48.2)$ & $1488(80.4)$ & $1247(37.7)$ & $281(25.4)$ \\
0 & $3239(51.7)$ & $362(19.6)$ & $2055(62.2)$ & $822(74.3)$ \\
1 & $5(0.1)$ & $0(0)$ & $2(0.1)$ & $3(0.3)$ \\
Missing & & $1283(69.4)$ & $2889(87.4)$ & $1068(96.6)$ \\
Chemotherapy & $5240(83.7)$ & $567(30.6)$ & $415(12.6)$ & $37(3.3)$ \\
0 & $1019(16.3)$ & $0(0)$ & $0(0)$ & $1(0.1)$ \\
1
\end{tabular}

${ }^{\mathrm{a}}$ Only data of one center in North America was available.

${ }^{\mathrm{b}}$ Global $p$ value for difference in distribution among continents

\section{APPENDIX 5: PATIENT AND DISEASE \\ CHARACTERISTICS INFLUENCING RTX RECOMMENDATION STRATIFIED \\ BY SPECIALTY}

\begin{tabular}{|c|c|c|c|c|c|c|}
\hline & Mean 5-poin & ikert scale sc & (standard err & of the mean) & & $p$ Value \\
\hline & Overall & $\begin{array}{l}\text { Medical } \\
\text { oncology }\end{array}$ & $\begin{array}{l}\text { Orthopedic } \\
\text { oncology }\end{array}$ & $\begin{array}{l}\text { Radiation } \\
\text { oncology }\end{array}$ & $\begin{array}{l}\text { Surgical } \\
\text { oncology }\end{array}$ & \\
\hline Age & $2.89(0.076)$ & $2.79(0.158)$ & $2.91(0.117)$ & $2.95(0.270)$ & $2.82(0.139)$ & 0.912 \\
\hline Depth & $3.96(0.071)$ & $4.20(0.139)$ & $3.94(0.105)$ & $3.95(0.301)$ & $3.78(0.157)$ & 0.270 \\
\hline Extent of tumor necrosis on MRI & $2.72(0.074)$ & $2.70(0.164)$ & $2.65(0.111)$ & $2.74(0.274)$ & $2.90(0.152)$ & 0.710 \\
\hline Gender & $1.38(0.044)$ & $1.26(0.073)$ & $1.38(0.065)$ & $1.21(0.123)$ & $1.58(0.131)$ & 0.097 \\
\hline Grade & $4.59(0.047)$ & $4.77(0.083)$ & $4.46(0.078)$ & $4.65(0.209)$ & $4.69(0.066)$ & 0.046 \\
\hline Histologic subtype & $4.44(0.049)$ & $4.47(0.103)$ & $4.36(0.076)$ & $4.30(0.206)$ & $4.65(0.078)$ & 0.178 \\
\hline Infiltrative growth pattern & $3.94(0.070)$ & $3.39(0.167)$ & $4.20(0.090)$ & $3.95(0.270)$ & $3.98(0.155)$ & $\mathbf{0 . 0 0 0}$ \\
\hline Localization & $4.16(0.060)$ & $4.21(0.123)$ & $4.17(0.087)$ & $4.20(0.156)$ & $4.02(0.160)$ & 0.774 \\
\hline Margin achieved & $4.58(0.055)$ & $4.62(0.113)$ & $4.52(0.090)$ & $4.60(0.210)$ & $4.67(0.078)$ & 0.785 \\
\hline Mitotic rate & $3.41(0.076)$ & $3.57(0.164)$ & $3.22(0.112)$ & $2.95(0.259)$ & $3.82(0.153)$ & 0.008 \\
\hline Performance score & $3.00(0.074)$ & $3.33(0.157)$ & $2.70(0.105)$ & $3.32(0.230)$ & $3.34(0.166)$ & 0.001 \\
\hline Presence of genetic prognostic maker(s) & $2.44(0.071)$ & $2.46(0.154)$ & $2.35(0.098)$ & $2.32(0.254)$ & $2.68(0.182)$ & 0.382 \\
\hline Presence of (other) oncologic diseases in history & $2.53(0.073)$ & $2.82(0.173)$ & $2.28(0.100)$ & $2.84(0.245)$ & $2.54(0.146)$ & 0.013 \\
\hline Resectability & $4.63(0.042)$ & $4.71(0.093)$ & $4.61(0.060)$ & $4.45(0.223)$ & $4.65(0.073)$ & 0.526 \\
\hline Size & $4.34(0.056)$ & $4.60(0.107)$ & $4.26(0.085)$ & $4.35(0.221)$ & $4.20(0.122)$ & 0.063 \\
\hline Tumor differentiation & $3.99(0.067)$ & $3.97(0.156)$ & $3.88(0.099)$ & $3.70(0.282)$ & $4.37(0.093)$ & $\mathbf{0 . 0 3 9}$ \\
\hline
\end{tabular}

${ }^{\mathrm{a}}$ Global $p$ value for difference in distribution among specialties 


\section{APPENDIX 6: PATIENT AND DISEASE CHARACTERISTICS INFLUENCING CTX RECOMMENDATION STRATIFIED BY SPECIALTY}

\begin{tabular}{|c|c|c|c|c|c|c|}
\hline & \multicolumn{5}{|c|}{ Mean 5-point Likert scale score (standard error of the mean) } & \multirow[t]{2}{*}{$p$ Value $^{\mathrm{a}}$} \\
\hline & Overall & $\begin{array}{l}\text { Medical } \\
\text { oncology }\end{array}$ & $\begin{array}{l}\text { Orthopedic } \\
\text { oncology }\end{array}$ & $\begin{array}{l}\text { Radiation } \\
\text { oncology }\end{array}$ & $\begin{array}{l}\text { Surgical } \\
\text { oncology }\end{array}$ & \\
\hline Age & $3.94(0.073)$ & $4.07(0.136)$ & $4.02(0.106)$ & $4.26(0.263)$ & $3.54(0.171)$ & 0.055 \\
\hline Depth & $3.58(0.082)$ & $3.97(0.158)$ & $3.60(0.116)$ & $3.72(0.351)$ & $2.83(0.188)$ & 0.000 \\
\hline Extent of tumor necrosis on MRI & $2.81(0.081)$ & $2.67(0.165)$ & $3.02(0.115)$ & $2.39(0.315)$ & $2.71(0.188)$ & 0.112 \\
\hline Gender & $1.40(0.046)$ & $1.38(0.098)$ & $1.43(0.066)$ & $1.22(0.129)$ & $1.39(0.120)$ & 0.752 \\
\hline Grade & $4.55(0.057)$ & $4.69(0.114)$ & $4.50(0.081)$ & $4.63(0.232)$ & $4.41(0.153)$ & 0.394 \\
\hline Histologic subtype & $4.73(0.038)$ & $4.76(0.087)$ & $4.70(0.050)$ & $4.83(0.090)$ & $4.69(0.110)$ & 0.803 \\
\hline Infiltrative growth pattern & $3.11(0.084)$ & $2.96(0.171)$ & $3.29(0.122)$ & $2.57(0.305)$ & $2.98(0.208)$ & 0.101 \\
\hline Localization & $3.36(0.084)$ & $3.73(0.156)$ & $3.32(0.122)$ & $3.22(0.348)$ & $2.85(0.202)$ & 0.012 \\
\hline Margin achieved & $3.56(0.084)$ & $3.65(0.162)$ & $3.53(0.126)$ & $3.72(0.266)$ & $3.39(0.203)$ & 0.745 \\
\hline Mitotic rate & $3.57(0.082)$ & $3.81(0.158)$ & $3.55(0.124)$ & $2.83(0.259)$ & $3.56(0.198)$ & 0.053 \\
\hline Performance score & $3.87(0.079)$ & $4.37(0.122)$ & $3.58(0.118)$ & $4.32(0.276)$ & $3.85(0.210)$ & 0.000 \\
\hline $\begin{array}{l}\text { Presence of genetic prognostic } \\
\text { maker(s) }\end{array}$ & $2.94(0.084)$ & $2.79(0.169)$ & $3.06(0.123)$ & $2.78(0.275)$ & $2.93(0.200)$ & 0.559 \\
\hline $\begin{array}{l}\text { Presence of (other) oncologic } \\
\text { diseases in history }\end{array}$ & $2.95(0.081)$ & $3.11(0.171)$ & $2.87(0.115)$ & $3.06(0.221)$ & $2.78(0.199)$ & 0.534 \\
\hline Resectability & $3.77(0.078)$ & $4.00(0.154)$ & $3.68(0.115)$ & $3.94(0.249)$ & $3.51(0.204)$ & 0.193 \\
\hline Size & $4.20(0.068)$ & $4.57(0.114)$ & $4.10(0.098)$ & $4.58(0.221)$ & $3.62(0.190)$ & 0.000 \\
\hline Tumor differentiation & $3.97(0.074)$ & $3.89(0.170)$ & $4.01(0.103)$ & $3.74(0.295)$ & $4.09(0.155)$ & 0.671 \\
\hline
\end{tabular}

${ }^{\mathrm{a}}$ Global $p$ value for difference in distribution among specialties

\section{REFERENCES}

1. WHO Classification of Tumours of Soft Tissue and Bone. 4th ed. International Agency for Research on Cancer (IARC), 2013.

2. Stiller CA, Trama A, Serraino D, et al. Descriptive epidemiology of sarcomas in Europe: report from the RARECARE project. Eur J Cancer. 2013;49:684-95. https://doi.org/10.1016/j.ejca.2012.0 9.011 .

3. Mastrangelo G, Coindre JM, Ducimetière F, et al. Incidence of soft tissue sarcoma and beyond: a population-based prospective study in 3 European regions. Cancer. 2012;118:5339-48. http s://doi.org/10.1002/cncr.27555.

4. Von Mehren M, Randall RL, Benjamin RS, et al. Soft tissue sarcoma, version 2.2018. NCCN ClinPract Guidelines Oncol. 2018;16:536-63.

5. Casali PG, Abecassis N, Aro HT, et al. Soft tissue and visceral sarcomas: ESMO-EURACAN Clinical Practice Guidelines for diagnosis, treatment, and follow-up. Ann Oncol. 2018;29(Suppl 4):iv51-67. https://doi.org/10.1093/annonc/mdy096.

6. Ray-Coquard I, Thiesse P, Ranchère-Vince D, et al. Conformity to clinical practice guidelines, multidisciplinary management, and outcome of treatment for soft tissue sarcomas. Ann Oncol. 2004;15:307-15. https://doi.org/10.1093/annonc/mdh058.

7. Derbel O, Heudel PE, Cropet C, et al. Survival impact of centralization and clinical guidelines for soft tissue sarcoma: a prospective and exhaustive population-based cohort. PLOS ONE. 2017;12:e0158406. https://doi.org/10.1371/journal.pone. 0158406 .
8. Heudel PE, Cousin P, Lurkin A, et al. Territorial inequalities in management and conformity to clinical guidelines for sarcoma patients: an exhaustive population-based cohort analysis in the Rhône-Alpes region. Int J ClinOncol. 2014;19:744-52. https://d oi.org/10.1007/s10147-013-0601-2.

9. Bagaria SP, Chang YH, Gray RJ, Ashman JB, Attia S, Wasif N. Improving long-term outcomes for patients with extra-abdominal soft tissue sarcoma regionalization to high-volume centers: improved compliance with guidelines or both? Sarcoma. 2018;2018:8141056. https://doi.org/10.1155/2018/8141056.

10. Rossi CR, Vecchiato A, Mastrangelo G, et al. Adherence to treatment guidelines for primary sarcomas affects patient survival: a side study of the European CONnectiveTIssueCAncerNETwork (CONTICANET). Ann Oncol. 2013;24:1685-91. https://doi.org/10.1093/annonc/md t031.

11. Pasquali S, Bonvalot S, Tzanis D, Casali PG, Trama A, Gronchi A. Treatment challenges in and outside a network setting: soft tissue sarcomas. Eur J SurgOncol. 2019;45:31-9. https://doi.org/ 10.1016/j.ejso.2017.09.015.

12. Acem I, Verhoef C, Rueten-Budde AJ, Grünhagen DJ, van Houdt WJ, van de Sande MAJ. Age-related differences of oncological outcomes in primary extremity soft tissue sarcoma: a multistate model including 6260 patients. Eur J Cancer. 2020;141:128-36. https://doi.org/10.1016/j.ejca.2020.09.021.

13. R: A Language and Environment for Statistical Computing. version 3.6.3. R Foundation for Statistical Computing, 2010. Retrieved xxxx at https://www.R-project.org/. Accessed 1 Oct 2020. 
14. Ngan R, Wang E, Porter D, et al. Soft-tissue sarcomas in the Asia-Pacific region: a systematic review. APJCP Asian Pac $J$ Cancer Prev. 2013;14:6821-32. https://doi.org/10.7314/apjcp.20 13.14.11.6821.

15. Atun R, Jaffray DA, Barton MB, et al. Expanding global access to radiotherapy. Lancet Oncol. 2015;16:1153-86. https://doi.org/10. 1016/s1470-2045(15)00222-3.

16. Pasquali S, Pizzamiglio S, Touati $\mathrm{N}$, et al. The impact of chemotherapy on survival of patients with extremity and trunk wall soft tissue sarcoma: revisiting the results of the EORTCSTBSG 62931 randomised trial. Eur J Cancer. 2019;109:51-60. https://doi.org/10.1016/j.ejca.2018.12.009.

17 Zaidi MY, Ethun CG, Tran TB, et al. Assessing the role of neoadjuvant chemotherapy in primary high-risk truncal/extremity soft tissue sarcomas: an analysis of the multi-institutional U.S. sarcoma collaborative. Ann SurgOncol. 2019;26:3542-9. https://d oi.org/10.1245/s10434-019-07639-7.

18. Callegaro D, Miceli R, Bonvalot S, et al. Development and external validation of two nomograms to predict overall survival and occurrence of distant metastases in adults after surgical resection of localised soft-tissue sarcomas of the extremities: a retrospective analysis. Lancet Oncol. 2016;17:671-80. https://d oi.org/10.1016/s1470-2045(16)00010-3.

19. van Praag VM, Rueten-Budde AJ, Jeys LM, et al. A prediction model for treatment decisions in high-grade extremity soft-tissue sarcomas: personalised sarcoma care (PERSARC). Eur J Cancer. 2017;83:313-23. https://doi.org/10.1016/j.ejca.2017.06.032.

20. Chibon F, Lagarde P, Salas S, et al. Validated prediction of clinical outcome in sarcomas and multiple types of cancer on the basis of a gene expression signature related to genome complexity. Nat Med. 2010;16:781-7. https://doi.org/10.1038/nm. 2174.

21. Valentin T, Lesluyes T, Le Guellec S, Chibon F. Chemotherapy in localized soft tissue sarcoma: will we soon have to treat grade 1 tumors? Update on CINSARC performances. Ann Oncol. 2019;30:153-5. https://doi.org/10.1093/annonc/mdy465.

22. Bertucci F, Finetti P, Monneur A, Birnbaum D. Pathological grade-independent prediction of chemosensitivity by CINSARC should rehabilitate adjuvant chemotherapy in soft tissue sarcomas of any grade. Ann Oncol. 2019;30:342-3. https://doi.org/10.109 3/annonc/mdy528.
23. Wasif N, Smith CA, Tamurian RM, et al. Influence of physician specialty on treatment recommendations in the multidisciplinary management of soft tissue sarcoma of the extremities. JAMA Surg. 2013;148:632-9. https://doi.org/10.1001/jamasurg.2013. 113.

24. Sherman KL, Wayne JD, Bilimoria KY. Overcoming specialty bias: another important reason for multidisciplinary management of soft tissue sarcoma. JAMA Surg. 2013;148:640. https://doi.org/ 10.1001/jamasurg.2013.143.

25. Rothermundt C, Whelan JS, Dileo P, et al. What is the role of routine follow-up for localised limb soft tissue sarcomas? A retrospective analysis of 174 patients. $\mathrm{Br} J$ Cancer. 2014;110:2420-6. https://doi.org/10.1038/bjc.2014.200.

26. Hovgaard TB, Nymark T, Skov O, Petersen MM. Follow-up after initial surgical treatment of soft tissue sarcomas in the extremities and trunk wall. ActaOncol. 2017;56:1004-12. https://doi.org/10. 1080/0284186x.2017.1299937.

27. Sakata K, Beitler AL, Gibbs JF, Kraybill WG, Virgo KS, Johnson FE. How surgeon age affects surveillance strategies for extremity soft tissue sarcoma patients after potentially curative treatment. $J$ Surg Res. 2002;108:227-34. https://doi.org/10.1006/jsre.2002. 6544.

28. Johnson FE, Sakata K, Kraybill WG, et al. Long-term management of patients after potentially curative treatment of extremity soft tissue sarcoma: practice patterns of members of the Society of Surgical Oncology. SurgOncol. 2005;14:33-40. https://doi.org/ 10.1016/j.suronc.2004.12.001.

29. Beitler AL, Virgo KS, Johnson FE, Gibbs JF, Kraybill WG. Current follow-up strategies after potentially curative resection of extremity sarcomas: results of a survey of the members of the society of surgical oncology. Cancer. 2000;88:777-85.

30. Gerrand CH, Billingham LJ, Woll PJ, Grimer RJ. Follow-up after primary treatment of soft tissue sarcoma: a survey of current practice in the United Kingdom. Sarcoma. 2007;2007:34128. https://doi.org/10.1155/2007/34128.

\section{Publisher's Note}

Springer Nature remains neutral with regard to jurisdictional claims in published maps and institutional affiliations. 